\title{
The Production of Jam from African Star Apple (Alasa) and Honey
}

\author{
Lucia Dzokoto $^{* 1} \quad$ Doris Tempah ${ }^{2}$ \\ 1.Department of Hospitality Management, Takoradi Technical University, Takoradi, Ghana \\ 2.Tamso Catholic Church, P. O. Box 210, Tarkwa, Ghana
}

\begin{abstract}
The main objective of this study was to produce jam using Alasa and honey. Experimental study design and sensory analysis techniques were applied. The study population consists of students and staff of the Hospitality Management department of Takoradi technical University. A sample size of 65 was purposively or conveniently selected. Two forms of data obtained primarily from the primary source include samples of raw materials with ingredients used and sensory form feedback obtained from the respondents. The raw materials were sourced locally. The data was analyzed using SPSS and Microsoft Excel 2013. The paper discovered that majority of the respondents know Alasa and have ever consumed it. Also, most of the respondents expressed their preference for Alasa with reasons pointing to its great natural taste and health benefits. In respect of the specific objectives, majority of the respondents accepted that jam can be produced from Alasa and honey given its rich source of protein and medicinal value. Majority agreed that jam made from Alasa and honey would be accepted in the Ghanaian community and expressed their desire for it to be produced both in local and global markets. The paper concludes with recommendations among other things that diabetic patients should try and patronize Alasa and honey jam, people should patronize Alasa and honey jam in other to introduce varieties to breakfast dishes, research into the health benefits of Alasa and honey jam should be encouraged and industries should produce Alasa and honey jam in large quantities after research uncovers its health benefits.
\end{abstract}

Keywords: Alasa, Experimental design, Honey, Jam, Production, Sensory analysis.

DOI: $10.7176 / \mathrm{FSQM} / 101-06$

Publication date:September $30^{\text {th }} 2020$

\section{INTRODUCTION}

Jams are solid gels made from fruit pulp or juice, sugar and added pectin. They can be made from single fruits or a combination of fruits. The fruit content should be at least $40 \%$. In mixed fruit jams the first-named fruit should be at least $50 \%$ of the total fruit added (Fellows, Franco \& Rios, 2006). Jam is a product made by boiling fruit and sugar to a thick consistency without preserving the shape of the fruit. Jams are bread dressings served alone or together with margarine or fresh butter. The major consumers are pastries, households, hotels, schools and military camps.

For decades, jams are made from a variety of fruits with high pectin contents and some vegetables such as mango, pineapple, orange, berries carrot and pumpkin. They are sometimes referred to collectively as preserves. The products are typically luxury items that are purchased by consumers in affluent urban areas (Fellows, Franco \& Rios, 2006).

Alasa or Abiu also known as the African Star Apple" and scientifically called Chrysophyllum Albidum is a tropical fruit that contain high amount of pectin, making it suitable for the production of jam. Alasa is an attractive, bright yellow fruit with a sweet, caramel flavoured, creamy-white pulp. It is produced on a small tree which grows well and flowers and fruits prolifically in north Queensland and around Darwin. The fruit is available 8 months of the year in Australia and has a good potential for commercial development. (Crane and Balerdi, 2016)

Alasa (Abiu) originates from the Amazon basin in South America where it may have been cultivated for some thousands of years by the Indians of the region. However, only in very recent years has it been 'discovered' and grown commercially outside its home range. It is grown to a limited extent in Florida, USA, in northern Australia and two years ago in Malaysia. (Love and Paul, 2001)

Alasa is spherical in shape about three centimeters in diameter with either 4,5 or 6 seeds. It is called "star" because a cross-section cut reveals a star-like shape in the inner portion of the fruit. "Apple" because of its spherical shape just like the apple. The deep orange to red fruit with its leaves and tree bark is said to have curative and nutritive properties, which are extremely beneficial to our wellbeing. (Kwesi, 2015)

In Ghana Alasa is a highly seasonal fruit, hardly available all year round except from December to April. For many, memories of ,alasae are linked with memories of

Christmas and New Year. In Ghana, it is cultivated in cocoa growing areas, savannah and forest area, mostly found in the East Akim area, it takes between seven to eight years to mature. (Antwi-Otoo, 2016)

The flesh is soft, gelatinous, translucent-white and each fruit has 1-4 large dark brown seeds. Abiu is eaten slightly chilled by halving the fruit and scooping out the flesh or by cutting the fruit into segments and eating alone or in a fruit salad. It can also be used for juice and in ice-cream. The fruit is rich in vitamins and minerals: thiamine 
$0.2 \mathrm{mg}$, riboflavin $0.2 \mathrm{mg}$, niacin $3.4 \mathrm{mg}$, vitamin C $49 \mathrm{mg}$, calcium $22 \mathrm{mg}$ and iron $1.8 \mathrm{mg}$ (Lim, 1998).

It has a surprisingly decent amount of Ascorbic Acid (Vitamin C). It could serve as a natural source of Antioxidant booster to remove free radicals from oxidative stress disorders, and its leaf extract contains Hypoglycemic (to treat Diabetes) and Anti-Platelet activities, although it also had toxic effects on some organs (Boateng, 2016). Eating star apple as a snack is a good choice as the calories are low and it provides no fat; however, this may not be enough calories to ease hunger pains and boost energy levels, as between-meal snacks are meant to do (Kwesi, 2015). In view of the above, the researcher seeks to produce jam using Alasa and honey.

Research conducted by the African Research Review reveals that, the African star fruit contains some of the vital nutrients needed by the body in daily doses. For example, the fruit is an excellent source of calcium and vitamin c, which goes a long way to strengthen bones and teeth and also reduces the intensity of abdominal bloating and cramps in women (Kwesi, 2015). According to Boateng, (2016) the nutritional elements present include vitamins B1 and B2, crude fibre, lipids, protein and Iron. The fruit also has traces of Potassium, phosphorous, magnesium, tannins and flavonoids. Both the skin and pulp of the Alasa contains much more ascorbic acid than what is found in oranges. The immune system, eyes and even skin benefits tremendously from the high content of vitamin C present in „Alasa ${ }^{e e}$. Despite the rich nutritional content of alasa, a lot of people find it difficult to consume because of its sour taste. The researcher therefore sought to produce jam using Alasa and honey that will make it easy for people to consume.

Primarily, the main objective of the study was to prepare jam using alasa and honey. The specific objectives include:

- To find out if Alasa and honey can be used in jam making.

- To ascertain whether Alasa and honey jam can be accepted into the consumer market.

- To evaluate whether people will prefer Alasa and honey jam to other jam in the market.

To achieve these objectives, the study sought to find answers to the following research questions:

- Can Alasa and honey be used in jam making?

- Will the Alasa and honey jam be accepted into the consumer market?

- Will people prefer Alasa and honey jam to other jam in the market?

The significance of this paper lies in the fact that it can help create varieties of jam onto the Ghanaian market and the world as a whole. Again, the study can create awareness of the new use of the Alasa fruit. Furthermore, the jam can also serve as an alternative product for diabetic people who prefer to have jam without sugar since some of the Alasa jam were made with only honey instead of sugar. Last but not least, the paper would serve as a reference for further research work.

\section{MATERIAL AND METHODS}

In this section, we present the research design, population and sample characteristics, sources of raw materials, sample collection, product development, sensory and data analyses.

\section{Research Design}

This study used experimental research design. An experimental research is a controlled study in which the researcher attempts to control the variables to achieve a required result. In this study the researcher controlled the variable to get the required results. Variables like honey, sugar and Alasa was controlled by measuring, heating and cooking to get the Alasa and honey jam.

\section{Population and Sample Characteristics}

Population simply refers to subject or members that conform to a set of specification. The population of interest to the researcher were Students, Teaching and Non-teaching staff of the Hospitality Management Department of Takoradi Technical University. The sample size was sixty-five (65) respondents, consisting of fifteen (15) students each from HND I, II, III (regular and evening) and ten (10) teaching and ten (10) non-teaching staff. This sample size was selected to get the views of students, teaching and non-teaching staff.

\section{Sources of Raw Materials}

All the raw materials were locally available in Takoradi market circle and Kojokrom market. The researcher sourced for freshly ripped Alasa fruits from KojoKrom Market a suburb of Takoradi. However, during the cause of production all rotten fruits were excluded.

\section{Sample Collection}

Freshly ripped Alasa fruits, honey, sugar and ginger were bought a week before production because of its scarcity in the market and also to get a good quality product.

\section{Product Development}

Wash fresh fruit after sorting

Deseed fruit and then mash to obtain the pulp.

Add sugar and stir well

Boil for about 15 minutes to ensure a complete dissolution,

Boil down quickly to desired consistence 
Allow to cool, fill the jar and seal.

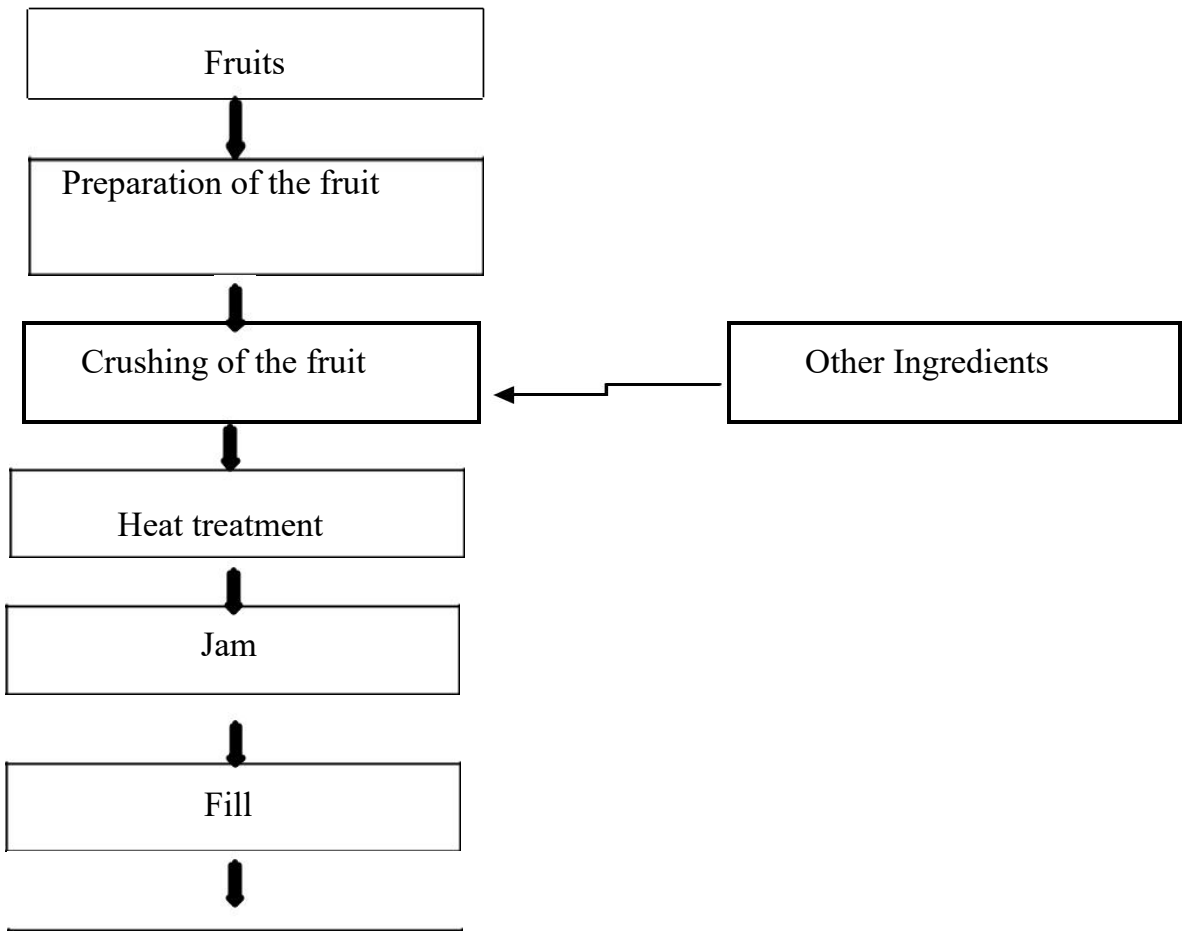

Pack and Seal

The products were produced at the Hospitality Management department of Takoradi Technical University. Strict food kitchen and personal hygiene practices were observed in the course of production. All equipment were thoroughly washed and rinsed, hand gloves were used during production.

Four different samples were produced;

Sample A: $\quad 100 \%$ sugar and Alasa Jam

Sample B: $\quad 50 \%$ Sugar, $50 \%$ honey and Alasa Jam

Sample C: $\quad 100 \%$ honey and Alasa Jam

Sample D: $\quad 40 \%$ Sugar, $60 \%$ Honey and Alasa jam.

\section{Sample A: $100 \%$ sugar and Alasa Jam}

Ingredients

$\begin{array}{ll}\text { Alasa } & 400 \mathrm{~g} \\ \text { Sugar } & 200 \mathrm{~g} \\ \text { Water } & 1 / 2 \text { liter }\end{array}$

Method

Ginger $5 \mathrm{~g}$

Wash, peel and deseed Alasa. Put them in a saucepan, add $1 / 2$ liter of water and bring to boil. Cover and leave to simmer for 15 minutes.

Use a blender to crush the cooked Alasa and remove the gummy particles.

Transfer the mixture into a new saucepan. Add sugar, ginger and cook on a medium heat. Cook till it gets thick and leaves the sides of the saucepan for 20-45 minutes.

Transfer into a new container and allow to cool.

Store in a cool dry place in an air tight container.

\section{Sample B:}

Ingredients

$\begin{array}{ll}\text { Alasa } & 400 \mathrm{~g} \\ \text { Sugar } & 100 \mathrm{~g} \\ \text { Honey } & 100 \mathrm{~g} \\ \text { Ginger } & 5 \mathrm{~g} \\ \text { Water } & 1 / 2 \text { liter }\end{array}$

Method

Water $\quad 1 / 2$ liter

Wash, peel and deseed Alasa fruits. Put them in saucepan, add $1 / 2$ liter water and bring to boil. Cover with a lid and 
simmer for 15 minutes until the Alasa are completely cooked.

Now crush in a blender and remove gummy particles. Transfer into a saucepan, add sugar, ginger and leave to simmer for 15 minutes.

Add honey and leave to simmer 20-25 minutes till thick and leaves the side of the saucepan.

Transfer into a new container and allow to cool.

Store in a cool dry place in an air tight container.

Sample C: $\mathbf{1 0 0 \%}$ honey and Alasa Jam

Ingredients

$\begin{array}{ll}\text { Alasa } & 400 \mathrm{~g} \\ \text { Honey } & 200 \mathrm{~g} \\ \text { Water } & 1 / 2 \text { liter } \\ \text { Ginger } & 5 \mathrm{~g}\end{array}$

Method

Wash, peel and deseed Alasa fruits. Put them in saucepan, add $1 / 2$ liter water and cook for 15 minutes.

Now crush the cooked Alasa in a blender, and remove gummy particles. Transfer into a saucepan, and simmer for 20 minutes.

Check on jam, add the honey and leave it to simmer for 15 minutes until it leaves the side of the pan.

Transfer into a clean container leave to cool.

Store in a cool dry place in an air tight container.

Sample D: 40\% Sugar, $60 \%$ Honey and Alasa Jam

Ingredients

$\begin{array}{ll}\text { Alasa } & 400 \mathrm{~g} \\ \text { Honey } & 150 \mathrm{~g} \\ \text { Sugar } & 50 \mathrm{~g} \\ \text { Water } & 1 / 2 \text { liter } \\ \text { Ginger } & 5 \mathrm{~g}\end{array}$

Method

Wash, peel and deseed Alasa. Put them in a saucepan, add $1 / 2$ liter of water and leave to simmer for 15 minutes.

Use a blender to crush the cooked Alasa and remove the gummy particles.

Transfer into a new saucepan. Add sugar and ginger and simmer for 20 minutes.

Check on jam and add honey and simmer until it leaves the sides of the saucepan for 15 minutes.

Transfer into a new container and allow to cool.

Store in a cool dry place in an air tight container.

\section{Sensory Analysis}

Samples from the products were displayed for the respondents to taste and comment using sensory analysis form.

The sensory indicators were texture, taste, aroma, colour and appearance by the use of questionnaires. The questionnaire consisted of both open and close ended questions. Open ended questions allowed respondents to share their views on the product whereas close ended questions allowed the respondents to choose from limited responses given.

Data Analysis

Data collected was analyzed using Statistical Package for Social Sciences and Microsoft Excel 2013. Results were presented using pie charts and frequency distribution tables for easy understanding of the results.

\section{RESULTS AND DISCUSSION}

This section presents analysis of data collected from Students, Teaching and None-Teaching staff of Takoradi Technical University at the department of Hospitality Management on the topic preparing jam using Alasa and honey. Sixty-five (65) copies of questionnaires were administered during the sensory evaluation stage and it is important to note that 50 of them were fully filled and returned, therefore the analysis was based on the fifty (50) questionnaire received. The analysis first presents the demographic data of respondents followed by the items in the questionnaires based on the objectives of the study.

\section{Demographic Characteristics}

It can be seen from Table 4.1 the frequency distribution of gender of respondents selected for the study. The table clearly indicates that majority of the respondents were females which recorded 35 respondents representing $70 \%$, while the remaining 15 respondents representing 30\% were males. This shows that more females participated in the study than males.

Table 4.1 also shows the frequency distribution of age of respondents who participated in the study. The table shows that the common age groups among the respondents were 18-25 years, which recorded 32 respondents representing $64 \%$, followed by age group between $26-35$ years, which recorded 16 respondents representing $32 \%$ 
and only 1 respondent representing $2 \%$ was above 45 years of age.

Table 4.1 further indicates the frequency distribution of educational status of the respondents who participated in the study. The table shows that HND III Hospitality Management students participated the more in the study (46\%), followed by HND I students recording 13 respondents representing $26 \%$.

Again, Table 4.1 indicates categories of respondents who participated in the study. It can be seen that majority of the respondents were students $(88 \%)$ while only $12 \%$ were staff. Out of the number of staff who took part in the study 50\% were teaching staff while the remaining 50\% were non-teaching staff. Hence there was a split.

Table 4.1 Background Information of Respondents

Employees

Characteristic

N Frequency $\quad$ Percent (\%)

\begin{tabular}{lcc}
\hline Gender & 50 & 30 \\
Male & 15 & 70 \\
Female & 35 & \\
Age & 50 & 64 \\
$18-25$ years & 32 & 32 \\
$26-35$ years & 16 & 2 \\
$36-45$ years & 1 & 2 \\
46 years and above & 1 & \\
Educational Level & 50 & 4 \\
Advance & 2 & 6 \\
Diploma & 3 & 26 \\
HND I & 13 & 10 \\
HND II & 5 & 46 \\
HND III & 23 & \\
Categories of & 50 & 12 \\
respondents & 6 & 88 \\
Staff & 44 & \\
Students & 3 & 50 \\
Categories of Staff & 3 & 50 \\
Teaching Staff & & \\
Nom & &
\end{tabular}

None teaching Staff

Figure 4.1 represents respondentse ${ }^{\text {ee }}$ awareness on Alasa and honey. When respondents were asked whether they have heard of Alasa and honey, majority of the respondents $(76 \%)$ said they have heard about Alasa and honey while $24 \%$ have not. This implies that Alasa is a common fruit that most people know. Antwi-Otoo (2016), stated that in Ghana

Alasa is available from December to April. For many, memories of „Alasa ${ }^{e c}$ are linked with memories of Christmas and New Year. In Ghana, it is cultivated in cocoa growing areas, savannah and forest area, mostly found in the East Akim area.

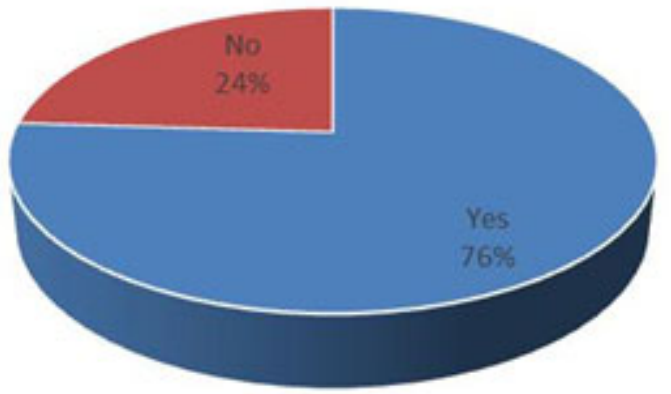

\section{Figure 4.1: Response on whether respondents have heard of Alasa and honey}

Source: Field work, March 2017

In Figure 4.2, respondents were asked whether they have eaten Alasa before. $86 \%$ of the respondents indicated that they have eating Alasa before. This implied that majority of the respondents have eaten Alasa before. According to Crane and Balerdi (2016), Alasa is usually eaten as a fresh fruit but may be an ingredient of sorbets and ice-cream. Alasa fruit contain vitamin A, ascorbic acid, phosphorous, and calcium. Doan (2016) added that a ripped Alasa has a very unique taste, the creamy white flesh is extremely delicate, lightly sweet, with a strong hint 
of caramel and vanilla.

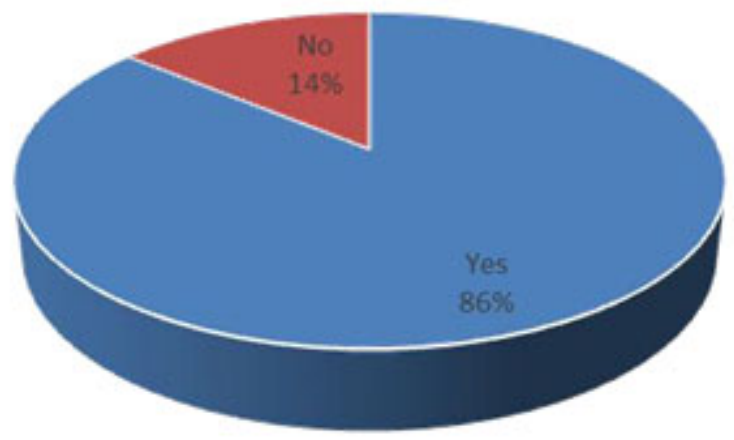

\section{Figure 4.2: Response on whether respondents have eaten Alasa before}

Source: Field work, March 2017

Respondents who said they have eaten Alasa before were asked a follow up question on the taste of Alasa. From Figure 4.3, majority of the respondents (68\%) said Alasa tasted Sour, 28\% of the respondents said it tasted sweet. This implied that majority of the respondents know that Alasa taste sour. This confirms the assertion by Crane and Balerdi (2016), that Alasa fruit contain high amount of ascorbic acid which makes it taste sour.

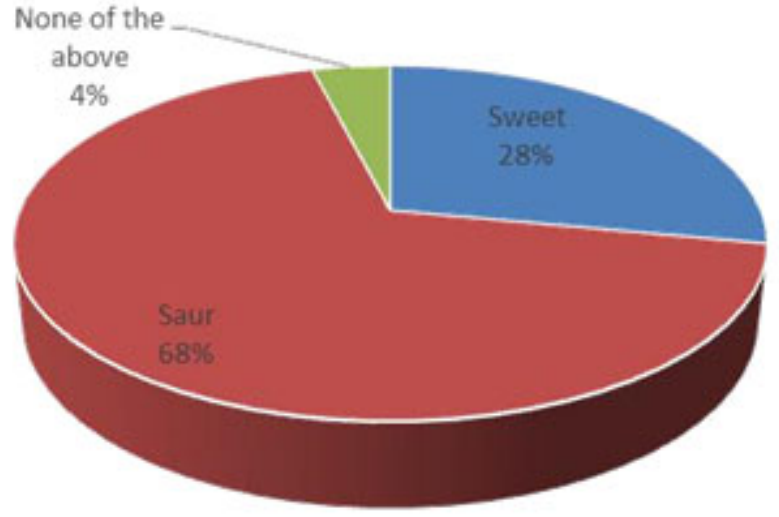

\section{Figure 4.3: The Taste of Alasa}

Source: Field work, March 2017

When respondents were asked what they know about Alasa (Table 4.2), more than half of them (64\%) mentioned that Alasa is a fruit and contain acid, about 32\% said it taste sweet but there is a little sourness in it, and only 4\% said Alasa is a healthy fruit and has a medicinal purpose. This is in line with the assertion of Boateng (2016), that the fruit is rich in vitamins and minerals: thiamine, riboflavin, niacin, vitamin $\mathrm{C}$, calcium and iron and has a medicinal purpose. In Brazil for instance, people use Alasa to relieve coughs, bronchitis and other pulmonary afflictions.

\section{Table 4.2 Respondents' Knowledge of Alasa}

\begin{tabular}{lll}
\hline Age & Frequency & Percentage (\%) \\
Alasa is fruit and contain acid & 32 & 64 \\
It taste sweet but sour & 16 & 32 \\
Healthy fruit and medicinal & 2 & 4 \\
Total & $\mathbf{5 0}$ & $\mathbf{1 0 0}$ \\
\hline
\end{tabular}

\section{Source: Field work, March 2017}

Figure 4.4 shows respondents' reaction to whether Alasa and honey can be used in jam making. Most of the respondents $(88 \%)$ believed that Alasa and honey can be used in jam making. This implied that, it is possible to use Alasa and honey to produce jam. The reason, as asserted by pickyourown.org, is that Alasa contains high amount of pectin, a substance which causes a thickening in the production of jams. 


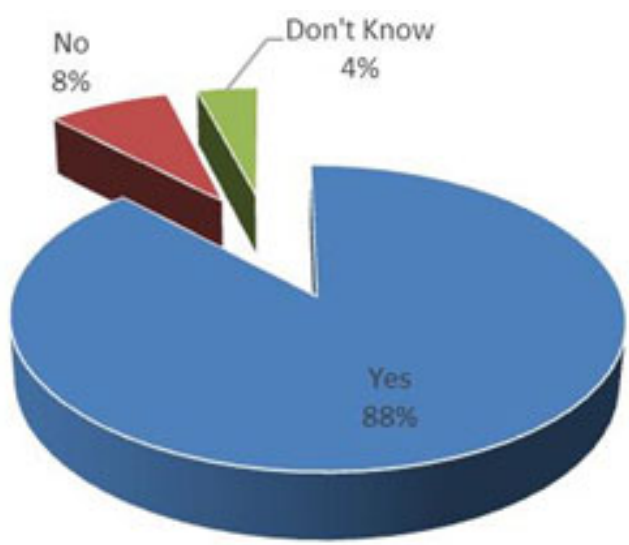

Figure 4.4: Response on whether Alasa and honey can be used in jam making Source: Field work, March 2017

Figure 4.5 shows respondents' views on foods or products made from Alasa and honey. Majority of the respondents $(84 \%)$ indicated that they have not come by any product made from honey and Alasa whilst $16 \%$ indicated that they have. This implied majority of the respondents have not seen any product made from Alasa. This indicate that not much products have been manufactured from Alasa on our market, so when a new product is made from Alasa, the Alasa eaters will be happy to patronize it.

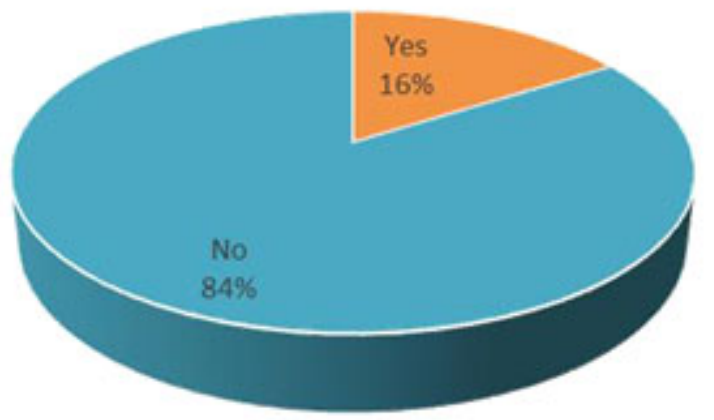

Figure 4.5: Response on whether respondents have seen any food or product made

from Alasa and honey.

\section{Source: Field work, March 2017}

Figure 4.6 shows response on whether consumers will accept Alasa and honey jam in the market. Majority of the respondents $(88 \%)$ agreed that honey and Alasa jam will be accepted by the Ghanaian community. This shows that when Alasa Jam is produced for the Ghana market more people will patronize it. The reason being that, people tend to be curious whenever there is a new product on the market.

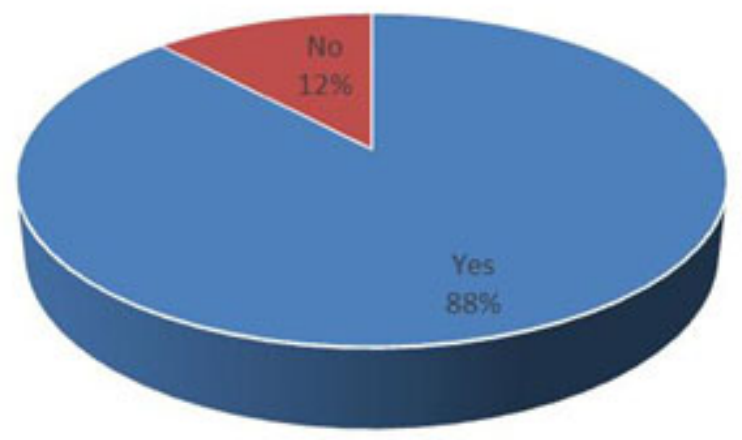

Figure 4.6: Acceptance of Alasa and honey jam.

Source: Field work, March 2017

Sensory Analysis

In this section, we analyzed respondents' view on the various products produced with the help of sensory analysis form. Product A, was Alasa and 100\% sugar jam, and Product B was 50\% honey, 50\% sugar and Alasa jam. 
Products $\mathrm{C}$ being the actual product was Alasa and $100 \%$ honey jam and product $\mathrm{D}$ was $40 \%$ Sugar, $60 \%$ honey and Alasa jam.

Table 4.3 shows respondents' views on Product A - jam made from Alasa and 100\% sugar. With the appearance of Alasa and sugar jam, $60 \%$ of the sample size admitted that it was excellent whiles $20 \%$ voted it to be very good. The Table revealed that Product A had an excellent colour as $40 \%$ said the colour was excellent. Another $40 \%$ said it was very good. With regards to the taste, $52 \%$ said the taste was excellent, $26 \%$ also said it was very good.

With regards to the aroma, 36\% admitted that the aroma was excellent and for $30 \%$ the aroma was good. Finally, there was a little comment on the after-taste of Product A as $40 \%$ of the respondents said the after taste was excellent, and $2 \%$ said it was poor. Therefore, Product A had a perfect appearance, good colour, nice taste, perfect aroma with no after taste. This analysis goes in line with Saffery, D. (2007), assertion that people find jam made with $100 \%$ sugar very delicious.

Table 4.3 Sensory Evaluation for Product A - (Alasa and100\% Sugar jam)

\begin{tabular}{|l|l|l|l|l|c|}
\hline Sensory & Excellent & Very Good & Good & Poor & Very poor \\
\hline Appearance & $30-60 \%$ & $10-20 \%$ & $9-18 \%$ & $1-2 \%$ & $0-0 \%$ \\
\hline Colour & $20-40 \%$ & $20-40 \%$ & $9-18 \%$ & $1-2 \%$ & $0-0 \%$ \\
\hline Taste & $26-52 \%$ & $13-26 \%$ & $10-20 \%$ & $1-2 \%$ & $0-$ \\
\hline Aroma & $18-36 \%$ & $17-34 \%$ & $15-30 \%$ & $0-0 \%$ & 0 \\
\hline After-taste & $20-40 \%$ & $16-15 \%$ & $13-26 \%$ & $1-2 \%$ & $0 \%$ \\
\hline
\end{tabular}

Source: Fieldwork March, 2017

Table 4.4 presents respondents view on Product B (Jam made from 50\% honey, 50\% sugar and Alasa). With regards to the appearance of Product B, $40 \%$ of the respondents said it was excellent whilst $16 \%$ indicated that it was very poor.

With the colour, majority of the respondents (32\%) said the colour was excellent whiles $14 \%$ said the colour was very poor. With regards to the taste of Product B, $44 \%$ declared the taste was excellent, and $12 \%$ voted it very poor.

The aroma of Product B was found to be excellent as 50\% of the sample size attested to that. However, $10 \%$ said the aroma was bad. $10 \%$ respondents made a little comment on the after-taste of Product B, indicating that it had very poor after-taste. Therefore, the appearance, colour, taste, after-taste and aroma of Product B were excellent.

Table 4.4 Sensory Evaluation for Product B - (50\% honey, 50\% Sugar and Alasa)

\begin{tabular}{|l|l|l|l|l|l|}
\hline Sensory & Excellent & Very Good & Good & Poor & Very poor \\
\hline Appearance & $20-40 \%$ & $5-10 \%$ & $10-20 \%$ & $7-14 \%$ & $8-16 \%$ \\
\hline Colour & $16-32 \%$ & $10-20 \%$ & $9-18 \%$ & $8-16 \%$ & $7-14 \%$ \\
\hline Taste & $22-44 \%$ & $7-14 \%$ & $7-14 \%$ & $8-16 \%$ & $6-12 \%$ \\
\hline Aroma & $25-50 \%$ & $9-18 \%$ & $6-12 \%$ & $5-10 \%$ & $5-10 \%$ \\
\hline After-taste & $0-0 \%$ & $0-0 \%$ & $0-0 \%$ & $0-0 \%$ & $5-10 \%$ \\
\hline
\end{tabular}

\section{Source: Fieldwork March, 2017}

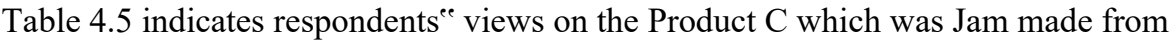

Alasa and honey. About $40 \%$ said the appearance of Alasa and honey jam was very good and only $4 \%$ of respondents said the appearance was poor.

The colour was regarded to be good by $40 \%$ of the respondents, whilst $4 \%$ of the population indicated that the colour was poor.

With regards to the taste $44 \%$ said it was good but $4 \%$ revealed that the taste of Alasa and honey jam was unpleasant. About the aroma of Alasa and honey jam, only $14 \%$ of the respondents indicated that the aroma was excellent, $66 \%$ indicated the aroma was good. $48 \%$ of the population made a poor comment on the aftertaste of 
Product C. Thus, Product $\mathrm{C}$ has a perfect appearance, good colour, nice taste with little aftertaste and perfect aroma. This analysis agrees with Sommer Leigh (2015), who asserted that a very sweet fruit and honey jam with no sugar can be made but one should know just the right amount to use.

Table 4.5 Sensory Evaluation for Product C - (Alasa and 100\% Honey Jam)

\begin{tabular}{|l|l|l|l|l|c|}
\hline Sensory & Excellent & Very Good & Good & Poor & Very Poor \\
\hline Appearance & $12-24 \%$ & $20-40 \%$ & $16-32 \%$ & $2-4 \%$ & $0-0 \%$ \\
\hline Colours & $9-18 \%$ & $19-38 \%$ & $20-40 \%$ & $2-4 \%$ & $0-0 \%$ \\
\hline Taste & $8-16 \%$ & $18-36 \%$ & $22-44 \%$ & $2-4 \%$ & $0-0 \%$ \\
\hline Aroma & $7-14 \%$ & $8-16 \%$ & $33-66 \%$ & $2-4 \%$ & $0-0 \%$ \\
\hline Aftertaste & $6-12 \%$ & $17-34 \%$ & $24-48 \%$ & $3-6 \%$ & $0-0 \%$ \\
\hline
\end{tabular}

Source: Fieldwork March, 2017

Table 4.6 presents respondents ${ }^{\text {ee }}$ views on the Product D which was a jam made from $40 \%$ sugar $60 \%$ honey and Alasa jam. With regards to the appearance, $40 \%$ rated it excellent and $14 \%$ said it was poor.

The colour was rated very poor by $12 \%$ of the respondents but $34 \%$ indicated that the colour was excellent. With regards to the taste of Product D, $52 \%$ declared the taste was excellent, and $20 \%$ claimed it was very good.

Concerning the aroma, $75 \%$ of the respondents found it to be excellent but $2 \%$ voted the aroma as very poor.

Finally, 10\% commented excellently on the aftertaste of Product D. Therefore, it can be concluded that Product D had a faultless appearance, good colour, palatable taste with little after taste and perfect aroma.

Table 4.6 Sensory Evaluation for Product D - (40\% Sugar, $60 \%$ Honey and Alasa)

\begin{tabular}{|c|c|c|c|c|c|}
\hline Sensory & Excellence & Very Good & Good & Poor & Very Poor \\
\hline Appearance & $20-40 \%$ & $8-16 \%$ & $15-30 \%$ & $7-14 \%$ & $0-0 \%$ \\
\hline Colours & $17-34 \%$ & $10-20 \%$ & $8-16 \%$ & $9-18 \%$ & $-12 \%$ \\
\hline Taste & $26-52 \%$ & $8-20 \%$ & $7-14 \%$ & $7-14 \%$ & $0-\quad 0 \%$ \\
\hline Aroma & $35-75 \%$ & $5-10 \%$ & $9-20 \%$ & $1-2 \%$ & $0-\quad 0 \%$ \\
\hline Aftertaste & $5-10 \%$ & $0-0 \%$ & $0-0 \%$ & $0-0 \%$ & $-0 \%$ \\
\hline
\end{tabular}

Source: Fieldwork March, 2017

When respondents were asked the product they enjoyed most, $50 \%$ chose Product A (100\% fruits and Sugar jam), and 50\% also chose Product B which is made up of 50\% honey, 50\% Sugar and Alasa jam. Product C, which was the actual product made of Alasa and honey jam attracted $20 \%$. The least enjoyed product was Product D made of $40 \%$ Sugar, $60 \%$ honey and Alasa jam. This result shows that majority of the respondents enjoyed Alasa and sugar jam against Alasa and honey jam as shown in Figure 4.7. 


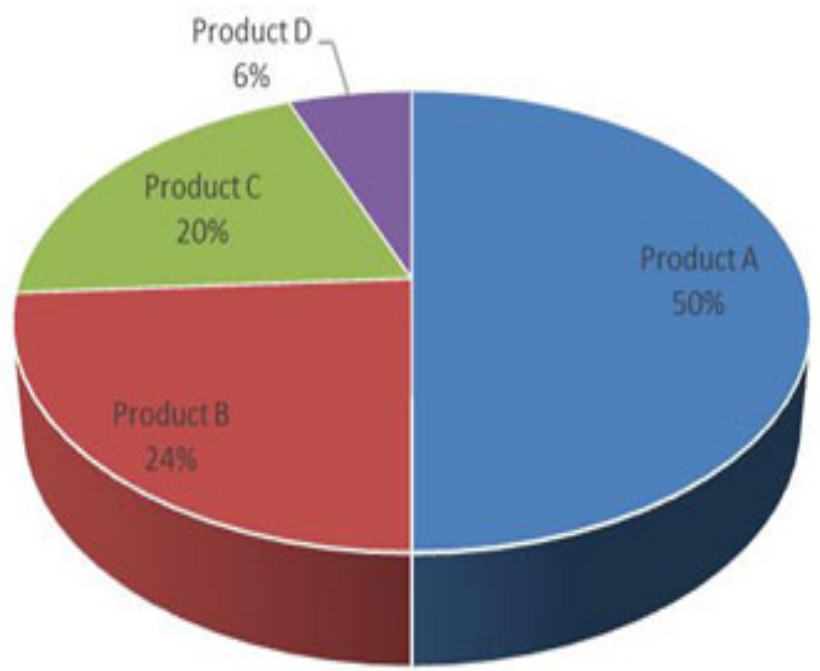

Figure 4.7: Which of the products did you enjoyed most?

Source: Fieldwork, March 2017

From figure 4.8 almost all the respondents ( $80 \%$ ) agreed that they would like the jam to be produced by Alasa and honey for the Ghanaian consumers and the world at large. This shows that when Alasa and honey jam is produced, people will patronize.

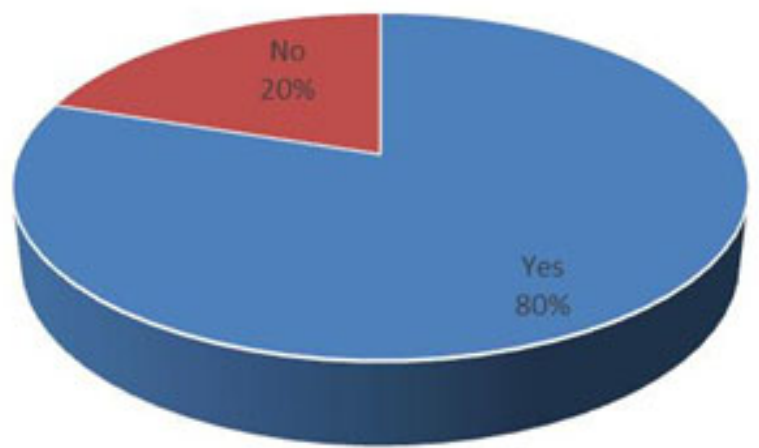

Figure 4.8: Would you like jam to be produced with Alasa and honey?

\section{Source: Fieldwork, March 2017}

When respondents were asked their opinion on whether they will prefer Alas and honey jam in the market (Figure 4.9), majority of the respondents (68\%) said yes and few said No (32\%). This implies that majority of the respondents sampled would prefer new type of jam in the market.

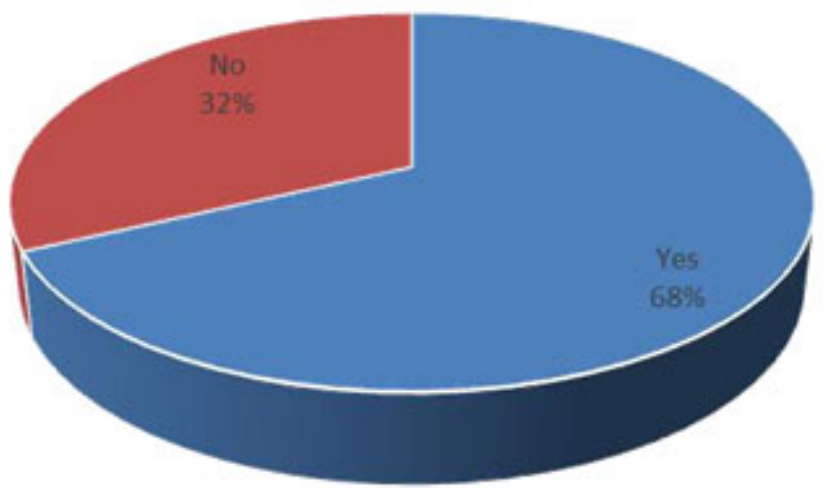

Figure 4.9: Do you think people will prefer Alasa and honey jam other jam in the market?

Source: Fieldwork, March 2017

Table 4.7 shows the reasons why respondents would prefer Alasa and honey Jam in the Ghanaian market. Majority of the respondents (64\%) said the product has great natural taste, $32 \%$ said the product has more health 
benefits and few (4\%) also stated that Alasa is a unique fruit.

Table 4.7 Reasons respondents prefer Alasa jam in the market

\begin{tabular}{lll}
\hline Responses & Frequency & Percentage (\%) \\
It has great natural taste & 32 & 64 \\
It has more health benefits & 16 & 32 \\
It is unique fruits & 2 & 4 \\
Total & $\mathbf{5 0}$ & $\mathbf{1 0 0}$ \\
\hline
\end{tabular}

Source: Field work, March 2017

Table 4.8 presents the result in respect of recommending the production of Alasa and Honey jam. More than half of the respondents $(56 \%)$ recommended that people should be educated to encourage them to eat Alasa thus patronize the jam and $24 \%$ of the respondents said Alasa Jam should be produced in large quantities for the Ghanaian market. About 16\% of the respondents recommended that Alasa jam should be promoted and only $4 \%$ of the respondents said there should be difference in appearance of the Alasa and honey jam.

\begin{tabular}{lll} 
Table 4.8 Recommendations regarding the production of Alasa and honey Jam \\
\hline Response & Frequency & Percentage (\%) \\
Alasa Jam should produce in large quantity & 12 & 24 \\
Educate people to patronise Alasa Jam & 28 & 56 \\
Should be promoted & 8 & 16 \\
There should be difference in appearance & 2 & 4 \\
Total & $\mathbf{5 0}$ & $\mathbf{1 0 0}$
\end{tabular}

\section{Source: Field work, March 2017}

\section{CONCLUSION AND RECOMMENDATION}

This section presents the conclusion and the recommendations of the study.

The purpose of the study was to prepare jam using Alasa and honey. The objectives were to find out if Alasa and honey can be used in jam making; ascertain whether Alasa and honey can be accepted into the consumer market; evaluate whether people will prefer Alasa and honey jam to other jams in the market.

The study found that more females $(70 \%)$ participated in the study than males, majority of the respondents who participated in the study were students with few teaching and none-teaching staff. It was found that majority of the respondents $(76 \%)$, have heard about Alasa and honey with $86 \%$ who have eaten some before, however, majority of the respondents $(68 \%)$ said Alasa tasted Sour. Also, it was found that majority of the respondents had not seen any product made from Alasa before.

The study revealed that respondents liked Alasa and honey jam because the product has great natural taste and has more health benefits. Respondents $(56 \%)$ recommended that people should be educated to encourage them to eat Alasa and thus patronize the jam. Alasa Jam should be produced in large quantities for the Ghanaian market. Also, some recommended that Alasa jam should be promoted to catch the attention of consumers.

In respect of our objectives, the following conclusions can be made based on the findings:

Most of the respondents (88\%) believed that Alasa and honey can be used in jam making since Alasa is a fruit that contains high amount of pectin which helps in the production of jam, and it is a healthy fruit and has a medicinal purpose.

Majority of the respondents (88\%) agreed that honey and Alasa jam will be accepted by the Ghanaian community.

Finally, a high percentage of the respondents $(80 \%)$ agreed that they would like jam to be produced using Alasa and honey for the Ghanaian consumers and the world at large and also majority of the respondents sampled would prefer Alas and honey jam in the market.

The paper recommends that:

Diabetic patient should try and purchase Alasa and honey jam.

Consumers should try and patronize Alasa and honey jam to create a variety in their breakfast dishes. It

is also recommended for students, travelers, caterers,

food vendors and other consumers.

Researchers can also research into the health benefits of alasa and honey jam.

It is also recommended that industrialist should use this research as a basis to produce alasa and honey jam in large quantities for the market.

Further studies can also be done on the colour of the jam to make it more attractive.

\section{References}

Adebisi A.A. (1997). Preliminary survey of post-harvest and marketing constraints of Chrysophyllum albidum

(African star apple) in Nigeria, Proceedings of a National workshop on the potentials of the star apple in 
Nigeria (eds.) Denton A. O., Oladipo D. O., Adetoro M. A. and Sarumi M. P. pp. 84-102.

Adisa S.A. (2000). Vitamin C, protein and mineral content of African star apple (Chrysophllum albidum). In: Proceedings of the 18th annual conference of NIST (eds.) Garba S. A., Ijagbone, I. F., Iyagba A. O., Iyamu A. O., Kitani A. S. and Ifaruna N. pp. 141-146.

Alasa is African star apple (Chrysophyllum albidum). Retrieved from https://www.spyghana.com/alasa-africanstar-apple-chrysophyllum-albidum/ .

Arotupin, D.J, Awojobi, K. O, Owolabi, T. R. and Eze, C. (2016). Microorganisms associated with African star apple (Chrysophylum albidum) and their hydrolases. ISSN 1996-0808, Vol. 10(7), pp. 225-230.

Boateng, S.K. (2016). Alasae - The Medicinal Fruit. Senior Research Scientist at the Plant Genetic Resources Research Institute.

Boning, D. (2006). ABIU - Emperor's Golden Fruit. AOAC International. Maryland. U.S.A.

Chay, A. (2011). Pearson 's composition and analysis of foods 9th Edition John Wily and sons Inc. New York. p. 57.

Chukumalume, R.C., Garba, S. A., Ijah, L. and Agary, A. (2010). Production and sensory evaluation of African star apple (Chrysophyllum albidum) fruit juice. Book of Extended Abstract of the 34th Annual Conference, Nigerian Instiute of Food Sc. \& Tech.

Crane E (1990). "Honey from honeybees and other insects". Ethology Ecology \& Evolution. 3 (sup1): 100-105. doi: 10.1080/03949370.1991.10721919.

Crane J.H. and Balerdi, C. F. (2016). Abiu Growing in the Florida Home Landscape. J.F. Morton Publ., Miami, Fla. P. 406-408 and Anon.

Crane, E., Walker, P., \& Day, R. (1984). Directory of important world honey sources. International Bee Research Association. ISBN 086098141X.

Crane, E.E. (1999). The World History of Beekeeping and Honey Hunting. Routledge. ISBN 9781136746703.

Falade K. Drying, sorption, sensory and microbiological characteristics of osmotically dried African star apple and African wild mango. PhD thesis. University of Ibadan; 2001.

Geiling, Natasha (2013). The Science behind Honey"s Eternal Shelf Life. Smithsonian.

Goldman, Ran D. (December 2014). "Honey for treatment of cough in children". Canadian Family Physician (Systematic review). 60 (12): 1107-1110. PMC 426480. PMID 25642485. Retrieved 15 October 2015.

Morton, (2011). Composition, Sensory characteristics and aroma profile of off vineripened mango (Mangifera indica L.). MSc Thesis, Sokoine Unversity of Agriculture, Morogoro, Tanzania, p78.

National Honey Board. "Carbohydrates and the Sweetness of Honey". Last accessed 1 June 2012.

Oregon State University "What is the relative sweetness of different sugars and sugar substitutes?". Retrieved 1 June 2012.

Oyelade OJ, Odugbenro PO, Abioye AO, Raji NL. Some physical properties of African star apple (Chrysophyllum albidum) seeds. J Food Eng. 2005; 67:435-440. doi: 10.1016/j.jfoodeng.2004.05.046.

Prescott, Lansing; Harley, John P.; Klein, Donald A. (1999). Microbiology. Boston: WCB/McGraw-Hill. ISBN 0697-35439-3.

Preserving Jam Maker Jams \& Jellies. https://www.freshpreserving.com/preserving-jam- maker-recipes.html

Saffery, D. (2007). The Ghana Cookery Book. Jeppestown Press. ISBN 978-0-9553936- 6-2.

Sidibe, M., and Williams J.T. (2002). Baobab (Adansonia digital L). Fruits for the Future. International Centre for underutilized Crops, Southampton, UK.

Sommer Leigh. How to Make Jam With Honey. Retrieved from http://www.livestrong.com/article/436594-howto-make-garden- huckleberryjam/

Tiisekwa, B.P.M, Ndabikunze B.K, Samson G, Juma M. (2002). Suitability of some indigenous Tree Fruits for Manufacturing juice and jam in Tanzania. In: Proceedings of the Region Agroforestry Conference. (Edited by ICRAF) 20-24 May, Warm baths, South Africa, p. 68.

Wills R, McGlasson B, Graham D, Joyce D (1998) Post-harvest. Anintroduction to the Physiology and Handling of fruits, vegetables and Ornamentals. 4th edition CAB International. 